\title{
Frequency and Predictors of Pulmonary Arterial Stump Thrombosis following Pneumonectomy or Lobectomy
}

\author{
Zerrin Gurel Durmus $^{\mathrm{a}}$ Yilmaz Bulbul ${ }^{\mathrm{a}}$ Celal Tekinbas ${ }^{\mathrm{b}}$ Kubra Nur Seyis ${ }^{\mathrm{b}}$ \\ Polat Kosucu ${ }^{\mathrm{C}}$ \\ aDepartment of Chest Diseases, Karadeniz Technical University School of Medicine, Trabzon, Turkey; \\ bepartment of Thoracic Surgery, Karadeniz Technical University School of Medicine, Trabzon, Turkey; \\ 'Department of Radiology, Karadeniz Technical University School of Medicine, Trabzon, Turkey
}

\section{Highlights of the Study}

- Pulmonary artery stump thrombosis following pneumonectomies is a rare condition of which the clinical importance is unknown.

- In this study, pulmonary artery stump thrombosis was detected in $4.5 \%$ of patients undergoing lobectomy/pneumonectomy.

- Pulmonary artery stump thrombosis was found to be significantly higher in subjects who underwent pneumonectomy, those with longer pulmonary artery stump, and those with pulmonary artery stump ligated by using stapler.

\section{Keywords}

Lobectomy · Lung cancer · Pneumonectomy · Pulmonary artery $\cdot$ Stump thrombosis $\cdot$ Thrombosis

\begin{abstract}
Objectives: Pulmonary artery stump thrombosis (PAST) following pneumonectomies/lobectomies is rare; its clinical importance is unknown. The objectives of this study were to analyze the prevalence and risk factors of PAST and the clinical significance in patients with pneumonectomy/lobectomy. Methods: All adult cases who underwent pneumonectomy/lobectomy in our hospital for any reason and who underwent control contrast-enhanced thoracic CT during the follow-up period were included in the study. Demographic
\end{abstract}

Karger@karger.com www.karger.com/mpp

Karger $\stackrel{\text { ' }}{5}$

GOPEN ACCESS
(C) 2022 The Author(s)

Published by S. Karger AG, Basel

This is an Open Access article licensed under the Creative Commons Attribution-NonCommercial-4.0 International License (CC BY-NC) (http://www.karger.com/Services/OpenAccessLicense), applicable to the online version of the article only. Usage and distribution for commercial purposes requires written permission. and clinical features of the patients, data on surgery, and the features of thrombi were recorded. Results: During the 4-year study period, a total of 454 patients underwent pneumonectomy/lobectomy (93 pneumonectomy and 361 lobectomy). Among the patients, 202 patients (50 pneumonectomy and 152 lobectomy) with at least one follow-up thorax CT were included in the analyses. PAST was detected in 9 (4.5\%) of 202 patients and mostly seen in patients with pneumonectomy (lobectomy: $2.6 \%$ vs. pneumonectomy: $10 \%, p=0.043$ ) and in patients whose pulmonary artery was ligated by using stapler (suture ligation $1 \%$ vs. stapler: $7.4 \%$, $p=0.034$ ). Pulmonary artery stump was also longer in patients with PAST $(8.48 \pm 11.22 \mathrm{~mm}$ vs. $23.55 \pm 11.22 \mathrm{~mm}, p<$ $0.001)$. Univariate logistic regression analysis showed that pneumonectomy and longer pulmonary artery stump length 
were found to be significantly associated with PAST ( $p=$ 0.041 and $p=0.001$, respectively). Conclusions: PAST was detected in $4.5 \%$ of our subjects undergoing lobectomy/ pneumonectomy. PAST was found to be significantly higher in subjects who underwent pneumonectomy, those with longer pulmonary artery stump, and those with pulmonary artery stump ligated by using stapler.

(C) 2022 The Author(s).

Published by S. Karger AG, Basel

\section{Introduction}

Pulmonary artery stump thrombosis (PAST) following pneumonectomies is a rare condition the clinical importance of which is still unknown. A few case reports and only three studies on limited numbers of patients with PAST have been published [1-6]. In two retrospective studies, the frequency of PAST after pneumonectomy was reported to be $12-12.4 \%[1,2]$. In these studies, it was reported that the development of PAST was more common in subjects who underwent right pneumonectomy and in subjects whose pulmonary artery stump was longer. Lopez-Padila et al. [3] reported that the frequency of PAST after pneumonectomy or lobectomy was $1.9 \%$, and it was confirmed that it developed more frequently, especially after right pneumonectomy. PAST is rarely accompanied by pulmonary embolism and is commonly regarded as a benign entity. Consequently, anticoagulation therapy is not generally recommended [4]. Due to the limited number of studies, there is insufficient information about PAST risk factors, follow-up, and treatment. Therefore, we studied the prevalence and risk factors of PAST and its clinical significance (follow-up, treatment, and resolution) in subjects with pneumonectomy or lobectomy.

\section{Methods and Subjects}

Following the approval of the Local Ethics Committee of Karadeniz Technical University Medical Faculty, the study was carried out in the Departments of Chest Diseases and Thoracic Surgery, retrospectively.

\section{Subjects}

We included in this study all adult cases who underwent pneumonectomy or lobectomy in our hospital between January 2014 and December 2018 for any reason (i.e., cancer or benign diseases) and who underwent control contrast-enhanced thoracic CT during the follow-up period. Subjects without contrast-enhanced thorax CT after surgery were excluded from the study. Demographical and clinical features of the subjects (smoking history, comorbid diseases, cancer history, thrombus risk factors, and anticoagulant use), data about surgery (dates and causes of surgery, histopathology results, pulmonary artery ligation techniques, and stage of malignant diseases), and the features of thrombi (location and resolution) were recorded.

\section{Statistical Analysis}

Data analysis was performed using SPSS software (IBM Statistics SPSS 22). The Kolmogorov-Smirnov test was performed to evaluate the suitability of the data for normal distribution. The $\chi^{2}$ test was used to compare categorical variables. The parametric Student $t$ test was used for comparing mean or median values of normally distributed data, and the nonparametric Mann-Whitney $U$ test was used to compare data that were not normally distributed. Univariate logistic regression analysis was performed for parameters likely to predict PAST.

\section{Results}

During the study period, a total of 454 subjects underwent pneumonectomy (93 subjects) or lobectomy (361 subjects). Among the subjects, 252 were excluded because they had no contrast-enhanced control thorax CT in our hospital system, and 202 subjects (50 with pneumonectomy and 152 with lobectomy) with at least one postoperative contrast-enhanced thorax CT were included in the analyses.

Of the 202 subjects included in the study, 173 (85.6\%) were male and 29 (14.4\%) were female (Table 1). The causes of surgery were primary lung malignancy in 185 subjects (91.5\%) and other diseases (metastasis from extrapulmonary malignancy or benign diseases such as bronchiectasis) in 17 subjects (8.5\%). Other diseases requiring surgery were bronchiectasis $(n=5,2.5 \%)$, metastasectomy $(n=4,2 \%)$, aspergilloma $(n=2,1 \%)$, bullous lung $(n=2,1 \%)$, and other causes $(n=4,2 \%)$.

During the follow-up period, PAST was detected in 9 $(4.5 \%)$ of 202 subjects and pulmonary embolism (PE) in 9 subjects $(4.5 \%)$ (Fig. 1, 2). One subject with PAST also developed PE during the follow-up period. PAST was detected in 5 subjects $(4.8 \%)$ who had undergone right lung operation and in 4 subjects $(4.3 \%)$ who had undergone left lung operation $(p=1.000)$. The surgical procedure in PAST subjects was thoracotomy in 8 (89\%) subjects and VATS in $1(11 \%)$ subject.

The histological types of all 9 subjects with PAST were not statistically different from 193 subjects without PAST. The mean time between the detection of PAST and the surgery was $133.4 \pm 173.6$ days (median: 108 days, range: 6-568 days). The mean time between surgery and control thorax CT was $113.9 \pm 175.3$ days (median: 59 days, range: 
Table 1. Distribution of demographic and clinical characteristics between subjects with or without pulmonary artery stump thrombi following pulmonary resection

\begin{tabular}{|c|c|c|c|}
\hline \multirow[t]{2}{*}{ Variables } & \multicolumn{2}{|c|}{$\begin{array}{l}\text { Pulmonary artery stump } \\
\text { thrombosis }\end{array}$} & \multirow[t]{2}{*}{$p$ value } \\
\hline & yes $(N=9)$ & no $(N=193)$ & \\
\hline Age, years & $70.1 \pm 7.4$ & $63.3 \pm 10.5$ & 0.059 \\
\hline \multicolumn{4}{|l|}{ Gender, $\%$} \\
\hline Male $(N=173)$ & $9-5.2$ & $164-94.8$ & \multirow[t]{2}{*}{0.363} \\
\hline Female $(N=29)$ & $0-0$ & $29-100$ & \\
\hline \multicolumn{4}{|l|}{$\mathrm{BMI}, \%$} \\
\hline $\mathrm{BMI} \geq 25$ & $5-3.8$ & $126-96.2$ & \multirow[t]{2}{*}{0.453} \\
\hline BMI $<25$ & $4-7.3$ & $51-92.7$ & \\
\hline \multicolumn{4}{|l|}{ Smoking, \% } \\
\hline Yes $(N=155)$ & $9-5.8$ & $146-94.2$ & \multirow[t]{2}{*}{0.600} \\
\hline No $(N=18)$ & 0 & $18-100$ & \\
\hline \multicolumn{4}{|l|}{ Comorbidity, $\%$} \\
\hline Yes $(N=140)$ & $7-5$ & $133-95$ & \multirow[t]{2}{*}{1.000} \\
\hline No $(N=56)$ & $2-3.6$ & $54-96.4$ & \\
\hline \multicolumn{4}{|l|}{ History of familial malignancy, $\%$} \\
\hline Yes $(N=45)$ & $5-11.1$ & $40-88.9$ & \multirow[t]{2}{*}{0.080} \\
\hline No $(N=62)$ & $1-1.6$ & $61-98.4$ & \\
\hline \multicolumn{4}{|l|}{ Immobilization, \% } \\
\hline Yes $(N=31)$ & $3-9.7$ & $28-90.3$ & \multirow[t]{2}{*}{1.000} \\
\hline No $(N=32)$ & $4-12.5$ & $28-87.5$ & \\
\hline \multicolumn{4}{|l|}{ Surgical procedure, $\%$} \\
\hline Lobectomy $(N=152)$ & $4-2.6$ & $148-97.4$ & \multirow[t]{2}{*}{0.043} \\
\hline Pneumonectomy $(N=50)$ & $5-10$ & $45-90$ & \\
\hline \multicolumn{4}{|c|}{ Pulmonary artery ligation technique, $\%$} \\
\hline Silk ligation $(N=97)$ & $1-1$ & $96-99.0$ & \multirow[t]{2}{*}{0.034} \\
\hline Stapler $(N=95)$ & $7-7.4$ & $88-92.6$ & \\
\hline \multicolumn{4}{|l|}{ Reason for surgery, \% } \\
\hline Lung cancer $(N=185)$ & $9-4.9$ & $176-95.1$ & \multirow[t]{2}{*}{1.000} \\
\hline Others $(N=17)$ & $0-0$ & $17-100$ & \\
\hline \multicolumn{4}{|l|}{ Stage of malignancy, $\%$} \\
\hline Stage $1-2(N=119)$ & $7-5.9$ & $112-94.1$ & \multirow[t]{2}{*}{0.721} \\
\hline Stage $3-4(N=63)$ & $2-3.2$ & $61-96.8$ & \\
\hline \multicolumn{4}{|c|}{ Histopathological types of malignancy, \% } \\
\hline Squamous cell $(N=81)$ & $6-7.4$ & $75-92.6$ & \multirow[t]{4}{*}{0.344} \\
\hline Adenocancer $(N=74)$ & $2-2.7$ & $72-97.3$ & \\
\hline Small cell $(N=4)$ & $0-0$ & $4-100$ & \\
\hline Others $(N=26)$ & $1-3.8$ & $25-96.2$ & \\
\hline Adjuvant chemotherapy, \% & & & \\
\hline Yes $(N=136)$ & $7-5.1$ & $130-94.9$ & 0.722 \\
\hline No $(N=63)$ & $2-3.2$ & $61-96.8$ & \\
\hline Mortality, \% & & & \\
\hline Exitus $(N=67)$ & $4-6$ & $63-94.0$ & 0.483 \\
\hline Alive $(N=135)$ & $5-3.7$ & $130-96.3$ & \\
\hline
\end{tabular}

* Comorbidities other than the current disease requiring surgery.
6-568 days) in those with PAST and $158.5 \pm 155.4$ days (median: 112 days, range: $3-1,126$ days) in those without PAST $(p=0.047)$ (Table 2).

We observed that PAST was seen most commonly in subjects with pneumonectomy $(p=0.043)$ and in subjects with pulmonary artery ligation by using stapler $(p=0.034)$
(Table 1). The length of the pulmonary artery stump was also longer in subjects with PAST (mean: $8.48 \pm 11.22 \mathrm{~mm}$, median: $4 \mathrm{~mm}$, range: $0-68$ vs. mean: $23.55 \pm 11.22 \mathrm{~mm}$, median: $26 \mathrm{~mm}$, range: $9-40 \mathrm{~mm}, p<0.001$ ).

Of the 9 subjects with PAST, 2 had presented to a physician with fever, 2 with dyspnea, and 1 with he- 
Table 2. Surgical procedures and outcomes of thrombus in subjects with pulmonary artery stump thrombi

\begin{tabular}{|c|c|c|c|c|c|c|}
\hline $\begin{array}{l}\text { Subject } \\
\text { No. }\end{array}$ & $\begin{array}{l}\text { Surgical } \\
\text { procedure }\end{array}$ & $\begin{array}{l}\text { Technique of } \\
\text { pulmonary } \\
\text { ligation }\end{array}$ & $\begin{array}{l}\text { Length of } \\
\text { pulmonary } \\
\text { stump, mm }\end{array}$ & $\begin{array}{l}\text { Duration between } \\
\text { surgery and detection } \\
\text { of thrombi, days }\end{array}$ & $\begin{array}{l}\text { Duration of } \\
\text { anticoagulant } \\
\text { therapy, months }\end{array}$ & $\begin{array}{l}\text { Last situation } \\
\text { of thrombi } \\
\text { (months) }\end{array}$ \\
\hline No. 1 & Right pneumonectomia & Stapler & 30 & 110 & 11 & Unchanged (48) \\
\hline No. 2 & Left lower lobectomy & Stapler & 16 & 568 & - & $\begin{array}{l}\text { Completely regressed } \\
\text { (20) }\end{array}$ \\
\hline No. 3 & Right bilobectomy inferior & Stapler & 12 & 26 & 20 & $\begin{array}{l}\text { Completely regressed } \\
\text { (11) }\end{array}$ \\
\hline No. 4 & Left pneumonectomia & Stapler & 26 & 59 & 3 & Unchanged (13) \\
\hline No. 5 & Right pneumonectomia & Stapler & 38 & 19 & 8 & Unchanged (4) \\
\hline No. 6 & Left upper lobectomy & Stapler + silk & 9 & 6 & 8 & Completely regressed (3) \\
\hline No. 7 & Left pneumonectomia & Stapler & 26 & 197 & - & Partially regressed (14) \\
\hline No. 8 & Right lower lobectomy & Silk & 15 & 108 & 7 & Unchanged (7) \\
\hline No. 9 & Right pneumonectomia & Stapler & 40 & 108 & - & Unknown \\
\hline
\end{tabular}

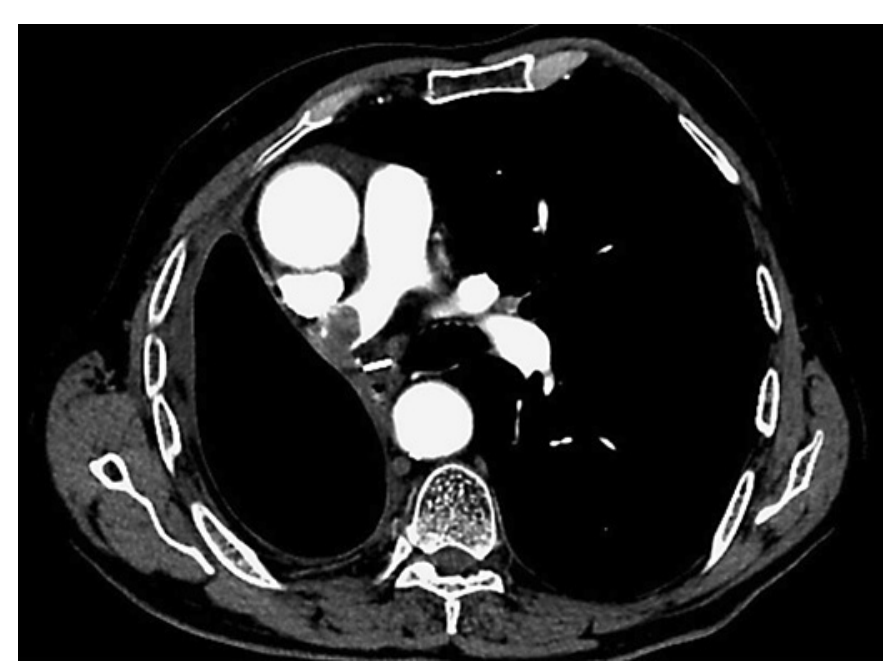

Fig. 1. Right pulmonary artery stump thrombosis in patient number 1 .

moptysis; however, 4 subjects were asymptomatic. After diagnosis of PAST, only 6 subjects were given anticoagulant therapy. The average anticoagulant treatment period was $9.5 \pm 5.7$ months (median: 8 months, range: 3-20 months). In follow-up, of the 3 subjects who were not given anticoagulant treatment, 1 had a complete resolution while 1 had partial resolution, and 1 was unknown because of death before obtaining control thorax CT. Of the 6 subjects who were given anticoagulant treatment, 2 had complete regression; however, no change was observed in PAST in 4 subjects. Univariate logistic regression analysis showed that

Pulmonary Artery Stump Thrombosis

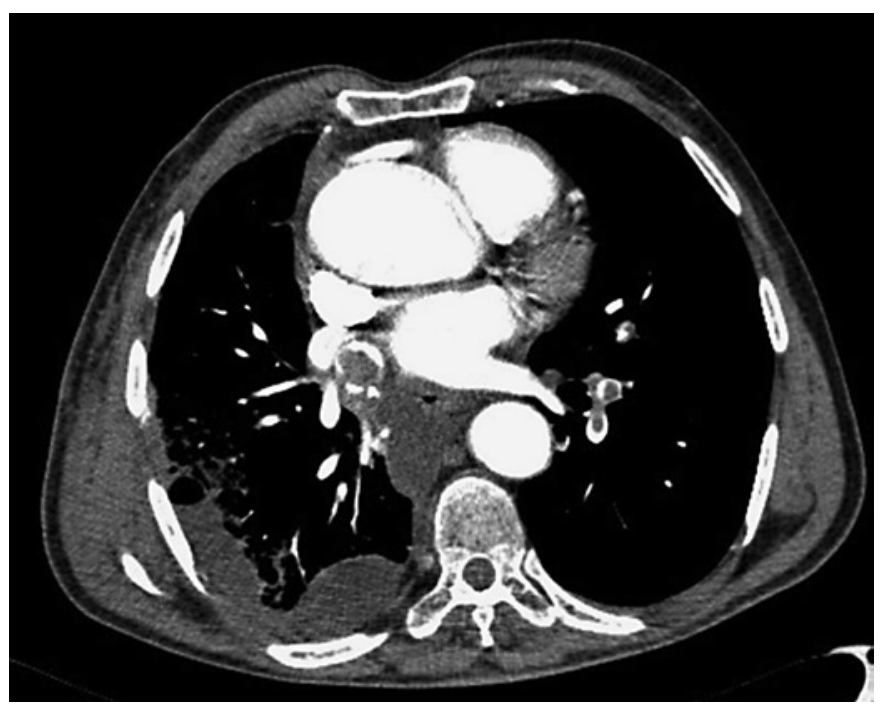

Fig. 2. Right pulmonary artery stump thrombosis and left lower lobe arterial embolism in patient number 3 .

pneumonectomy and longer pulmonary artery stump length were found to be significantly related to PAST ( $p=0.041$ and $p=0.001$, respectively) (Table 3 ).

\section{Discussion}

We found that $4.5 \%$ of subjects developed PAST after pneumonectomy or lobectomy in our study. PAST was detected in $12.2 \%$ of 147 pneumonectomy cases in a previous study [1] and in $12.4 \%$ of 89 pneumonectomy cases in another study [2]. This rate was $1.9 \%$ ( 9 of 473 subjects) 
Table 3. Analysis of parameters predicting pulmonary artery stump thrombosis using univariate logistic regression

\begin{tabular}{llll}
\hline Variables & Odds ratio & $95 \% \mathrm{Cl}$ & $p$ value \\
\hline Age & 1.074 & $0.997-1.158$ & 0.061 \\
$\mathrm{BMI}(\mathrm{BMI} \geq 25)$ & 1.976 & $0.510-7.658$ & 0.324 \\
History of familial malignancy & 7.625 & $0.859-67.706$ & 0.068 \\
Comorbidity & 1.421 & $0.286-7.059$ & 0.667 \\
Immobilization & 0.750 & $0.154-3.663$ & 0.722 \\
Travel $>12 \mathrm{~h}$ & 0.571 & $0.054-6.079$ & 0.643 \\
Adjuvant chemotherapy & 1.642 & $0.331-8.140$ & 0.544 \\
Recent surgery - trauma & 1.009 & $0.243-4.195$ & 0.990 \\
Type of operation (pneumonectomy/lobectomy) & 4.111 & $1.059-15.961$ & $\mathbf{0 . 0 4 1}$ \\
Length of bronchial arterial stump & 1.068 & $1.026-1.112$ & $\mathbf{0 . 0 0 1}$ \\
Pulmonary artery ligation technique (stapler vs. suture) & 7.651 & $0.922-63.463$ & 0.059 \\
\hline
\end{tabular}

in a study including both lobectomy and pneumonectomy subjects [3]. Although the PAST frequency was relatively higher in the first two studies involving subjects who underwent pneumonectomy only $[1,2]$, our results were similar to the PAST rates found in the study by Lopez-Padilla et al. [3] which included both subjects with pneumonectomy and lobectomy.

In our study, we found that all PASTs developed in subjects with lung cancer (6 squamous cell cancer, 2 adenocarcinoma, and 1 large cell neuroendocrine carcino$\mathrm{ma})$. Although it is difficult to make a unequivocal conclusion due to the scarcity of PAST numbers, similar results were reported in the study by Lopez-Padilla et al. [3] who found that all PAST subjects had pulmonary malignancy and similar histopathologic subtypes (4 squamous cell cancer, 4 adenocarcinoma, and 1 large cell carcinoma) [3]. Kim et al. [1] also showed that 15 of 18 PAST cases had squamous cell carcinoma while 3 had adenocarcinoma. Thus far, PAST has not been studied in subjects who underwent pneumonectomy/lobectomy for reasons other than primary lung malignancy. During our study, the number of subjects operated for non-lung cancer disease was 104; however, control contrast-enhanced thorax CT was obtained in only 17 of them. PASTs could have been neglected possibly because control thorax CT was not performed in most of these subjects after pneumonectomy/lobectomy.

Lopez-Padilla et al. [3] showed that 6 out of 9 pulmonary artery stump thrombus and Kim et al. [1] showed that 14 out of 18 pulmonary artery stump thrombus were on the right hemithorax. In our study, we did not observe such a relationship; however, we found that PAST was more frequent in cases with pneumonectomy than with lobectomy. As PAST was not looked at in previous studies on subjects with pneumonectomy versus lobectomy, further studies are needed for comparison $[1,3]$.

It has been reported that the probability of thrombus increases as the length of the pulmonary artery stump increases [1,2]. Kwek et al. [2] found that the length of the pulmonary artery stump in subjects with PAST was $40 \pm$ $14 \mathrm{~mm}$ on the right and $21 \pm 11 \mathrm{~mm}$ on the left; however, it was $30 \pm 9 \mathrm{~mm}$ on the right and $12 \pm 6 \mathrm{~mm}$ on the left in subjects without PAST. Kim et al. [1] also found the pulmonary artery stump to be longer in subjects with PAST $(37.2 \pm 6.8 \mathrm{~mm}$ in those with PAST and $12.5 \pm 25$ $\mathrm{mm}$ in those without PAST). Similarly, in our study, the average stump length was $8 \mathrm{~mm}$ in those who did not have PAST, and the average length of stump was $23 \mathrm{~mm}$ in those who had PAST and the risk of developing thrombus was increasing as the stump length increased. On the other hand, the pulmonary artery ligation technique requires attention since the development of PAST (suture vs. staplers) was higher in those by staplers $(p=0.034)$. Isik et al. [7] reported that thrombus formation in the pulmonary artery stump is more likely to occur following the closure of the stump with the transfixation ligature technique compared with the continuous ligature technique.

We found no relationship between the development of pulmonary artery stump thrombus and the gender, body mass index, smoking status, malignancy stage, comorbidity, immobility, and chemotherapy status. We suggest that more comprehensive studies are needed to conclude unequivocally on these relationships.

In our study, thrombus was stable in 4 of 9 cases with PAST, 3 were completely regressed and 1 was partially regressed (1 subject could not be evaluated). It was determined that 4 of 4 subjects with stable PAST and 2 of 3 subjects with complete regression in their PAST received anti- 
coagulant treatment. Although the number of cases is quite limited, we concluded that administration of anticoagulant therapy did not affect the outcome of PAST in more than half of the subjects. We also observed that PAST usually appeared in the first 6 months (mean: 133 days) after the operation, and that there was no relationship between the regression or occurrence of PAST in the first 6 months and later. On the contrary, Lopez-Padilla et al. [3] showed that PAST, which appeared in the first 12 months after surgery, was more likely to resolve, while those developing after 12 months resolved more slowly. In the same study, 7 of 9 subjects with PAST were given anticoagulant therapy, and PAST was resolved in 6 subjects with PAST ( 2 of them without using anticoagulant therapy). Kim et al. [1] found the mean time between stump thrombus and the surgery to be 14.8 months (range: 4.4, max: 61.2 months) [3].

The most important limitation of our study is the limited number of cases with PAST as in previous studies [3]. The low number of PAST cases did not allow for multivariate analysis to investigate risk factors and to ascertain the effectiveness of treatment and the course of PAST. Also, no conclusion could be drawn on whether perioperative anticoagulant prophylaxis helps prevent PAST, and the possible role of underlying hypercoagulopathy has not been studied.

\section{Conclusion}

PAST was detected in $4.5 \%$ of our subjects undergoing lobectomy/pneumonectomy. PAST was found to be significantly higher in subjects who underwent pneumonectomy, those with longer pulmonary artery stump, and those with pulmonary artery stump ligated by using stapler. We could not make a conclusion on the effect of anticoagulant use in terms of the fate of the thrombus; this issue needs to be studied in larger series.

\section{Statement of Ethics}

The study complies with the guidelines for human studies and was conducted ethically in accordance with the World Medical Association Declaration of Helsinki. Written informed consent was not obtained from the patients, because of the retrospective nature of the study. This study protocol was reviewed and approved by the Local Ethics Committee of Karadeniz Technical University Faculty of Medicine (Date/Number: April 24, 2017/24237859244).

\section{Conflict of Interest Statement}

The authors declare no potential conflicts of interest with respect to the research, authorship, and/or publication of this article.

\section{Funding Sources}

The authors received no financial support for this study.

\section{Author Contributions}

Conceptualization of the study: Y.B. and Z.G.D. Data collection: Z.G.D. and K.N.S. Data analysis: Y.B., C.T., and P.K. Writing of the first draft: Z.G.D. and Y.B. All authors contributed substantially to the final draft of the paper and its revisions. All authors have read and approved the final manuscript.

\section{References}

1 Kim SY, Seo JB, Chae EJ, Do KH, Lee JS, Song JW, et al. Filling defect in pulmonary arterial stump on CT after pneumonectomy: radiologic and clinical significance. Am J Roentgenol. 2005; 185:985-8.

2 Kwek BH, Wittram C. Postpneumonectomy pulmonary artery stump thrombosis: CT features and imaging follow-up. Radiology. 2005;237:338-41.
3 López-Padilla D, Peghini Gavilanes E, Revilla Ostolaza TY, Trujillo MD, Martínez Serna I, Arenas Valls N, et al. Arterial stump thrombosis after lung resection surgery: clinical presentation, treatment and progress. Arch Bronconeumol. 2016;52:512-8.

4 Joshi M, Farooq U, Mehrok S, Srouji N. Delayed formation of pulmonary artery stump thrombus: a case report and review of the literature. Thromb J. 2009;7:7-3.

5 Gorospe L, Jover-Díaz R, Muñoz-Molina GM. Bland or tumor pulmonary artery stump thrombosis? Asian Cardiovasc Thorac Ann. 2018;26:164-5.
6 Akcam TI, Kaya SO, Samancilar O, Ceylan KC. Pulmonary artery stump thrombosis developed during the late postoperative period. Kardiochir Torakochirurgia Pol. 2016;13: 260-1.

7 Isik F, Kara M, Tunçogur B, Sak SD, Kavukcu S. Significance of ligature technique on the formation of pulmonary artery stump thrombosis in a canine model. Acta Chir Belg. 2005; 105:203-6. 